Goldschmidt 2021 Abstract

https://doi.org/10.7185/gold2021.5093

\section{The lithospheric mantle as a "sink" and "source" in global volatile cycles}

\section{SALLY A. GIBSON}

University of Cambridge

Presenting Author: sally@esc.cam.ac.uk

The subcontinental lithospheric mantle represents one of Earth's most ancient and long-lived chemical reservoirs. It has a unique ability to both sequester volatiles (via metasomatism) and release them during volcanism, and so plays a critical role in modulating the out flux of these and other elements from our planets deep interior to its atmosphere. The widespread generation of deep-sourced, volatile-rich melts in Earth's mantle is borne out by global maps of magmas rich in $\mathrm{CO}_{2}, \mathrm{H}_{2} \mathrm{O}, \mathrm{S}$ and $\mathrm{F}$ (e.g. kimberlites, lamproites and carbonatites). Moreover, mantle xenoliths derived from the lower part of the lithospheric 'lid' preserve evidence of repeated episodes of pervasive, reactive percolation and stalling of these volatile-rich melts.

High-precision SIMS and FTIR analyses of volatile elements in the abundant nominally-volatile-free mantle minerals and in accessory phases, together with analyses of volatiles erupted from intraplate magmas, allow quantification of the storage of volatile elements in the lithospheric mantle, including those essential for life (C, H, S, F, Cl, Li). A major outstanding goal in understanding the cycling of these elements involves reducing uncertainties in the volume estimates of the lithospheric mantle at different tectonic settings. Lithospheric thickness estimates from multi-mode surface wave global tomography significantly reduce uncertainties in calculated volumes of lithospheric mantle and allow internally consistent estimates for the world's cratons, continental off-craton regions and oceans. The results show that the greatest repository for $\mathrm{C}, \mathrm{H}, \mathrm{S}, \mathrm{F}, \mathrm{Li}$ and $\mathrm{Cl}$ is in the mantle beneath global cratons; primarily because of this regions large volume and high concentrations of volatiles (Figure 1). The stability of sub-cratonic mantle during major rifting and heating events ensures that this reservoir has been a major global "sink" for volatiles throughout the last 2.5 billion years of Earth's evolution. In contrast, the volatiles that accumulate in off-craton mantle may have relatively short residence times and potentially be remobilised soon after their sequestration, e.g. during continued extension or heat conduction that accompanies the formation of an individual Large Igneous Provinces. Continental off-craton mantle may therefore transition from a volatile "sink" to "source" over very short geological timescales (a few million years).

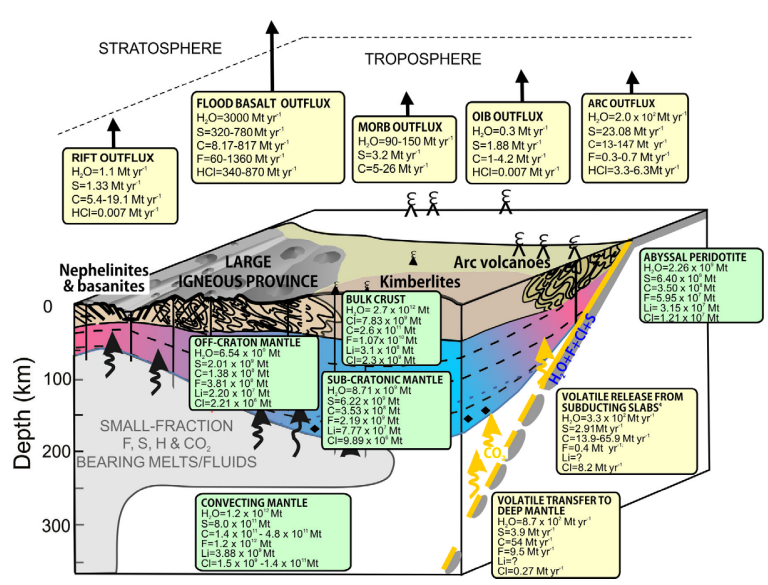

